\title{
Farmakokutsadura eta Garapen Iraunkorrerako 6. Helburua: ur garbia eta saneamendua
}

\author{
(Drug pollution and Sustainable Development 6th Goal: \\ clean water and sanitation)
}

\author{
Saioa Domingo Echaburu*1, Unax Lertxundi Etxebarria ${ }^{2}$, Gorka Orive Arroyo ${ }^{3}$ \\ ${ }^{1}$ Osakidetza, Debagoieneko ESI, Farmazia Zerbitzua (Arrasate, Gipuzkoa) \\ ${ }^{2}$ Bioaraba Osasun Ikerketa Institututa, Osakidetza, \\ Arabako Osasun Mentaleko farmazia zerbitzua (Vitoria-Gasteiz, Araba) \\ ${ }^{3}$ NanoBioCel Farmazia eta Farmazia Teknologia laborategiko ikerketa taldea, \\ Farmazia Fakultatea (UPV-EHU, Vitoria-Gasteiz, Araba)
}

\begin{abstract}
LABURPENA: Medikamentuek naturan duten inpaktua geroz eta interes handiagoa pizten duen gaia da. Ezaguna da medikamentuak eta haien hondakinak ingurumen-konpartimentu guztietan aurkitu direla, batez ere uretan. Medikamentuak ingurumenera iristeko bide nagusia kontsumoarekin eta haren ondoriozko iraizpenarekin dago erlazionatuta. Nolanahi ere, medikamentuen bizi-zikloaren beste faseetan ere gerta daitezke ingurumenerako igorpenak. Farmakokutsadurak eragina du ingurumenean dauden izaki bizidunetan, eta baita giza osasunean ere. Antibiotikoekiko erresistentzien gorakada da horren adibideetako bat. Bestalde, uraren erabilgarritasuna, saneamendua eta higienea giza eskubideak badira ere, mundu osoko biztanle guztiek ez dauzkate bermatuta. Artikulu honetan, Garapen Iraunkorrerako 6. Helburua $(\mathrm{GIH})$ - hots, ur garbia eta saneamendua - eta haren erronkak aztertuko ditugu, farmakokutsaduraren ikuspuntutik, konponbideak aztertuz. GIHek garrantzi berezia dute garapen-bidean dauden herrialdeetan; hain zuzen ere, uretako farmakokutsadura gehien dutenetan. Farmakokutsadura ulertu eta aztertzeko, «One-Health» ikuspuntua bultzatu beharra dago, hau da, osasun bakarrean bateratzea gizakion osasuna, animaliena eta partekatzen dugun ingurumenarena, eta, arazoari aurre egiteko, nahitaezkoa da medikamentuen bizi-zikloan parte hartzen duten eragile guztien elkarlana. Farmakokutsadura 6. GIHa lortzeko oztopo bihur ez dadin, beharrezkoa da lekuan lekuko osasun publikoaren beharrez gain neurrien kostu-eraginkortasuna ere kontuan hartzea, neurrien eraginkortasuna ziurtatzeko.
\end{abstract}

HITZ GAKOAK: farmakokutsadura, medikamentuak, garapen iraunkorrerako helburuak, ura, uretako kutsatzaileak.

ABSTRACT: The environmental impact of drugs or pharmaceuticals is a topic of growing concern. Drugs have been found in all environmental compartments, especially in water. Although the main route of access to the environment for drugs is related to consumption and resulting excretion, emissions can occur in any of the complex life cycle of pharmaceuticals. Apart from their ecotoxicological effects, pharmaceuticals in the environment can also affect human health (e.g: antibiotic resistance). In this article, we will focus on the potential influence of drug pollution on the $6^{\text {th }}$ Sustainable Development Goal (SDG), describing possible solutions. SDGs have a special relevance in developing countries, where water is more polluted with drugs. The «One-Health» approach, which considers the relationship between humans, animals, and the shared environment, is needed to understand drug pollution. Collaboration of all the stakeholders involved in the life cycle of drugs is mandatory. Considering the cost-effectiveness and sustainability of the measures will be necessary to prevent drug pollution from becoming an obstacle to obtaining the $6^{\text {th }} S D G$.

KEYWORDS: drug pollution, pharmaceuticals, sustainable development goals, water, aquatic pollutants.

\footnotetext{
* Harremanetan jartzeko / Corresponding author: Saioa Domingo Echaburu, Debagoeieneko ESlko Farmazia Zerbitzua, Nafarroa etorbidea 16 (20500 Arrasate-Gipuzkoa).. - saioa.domingoechaburu@osakidetza.eus - https://orcid.org/0000-00020642-9081.

Nola aipatu / How to cite: Domingo Echaburu, Saioa; Lertxundi Etxebarria, Unax; Orive Arroyo, Gorka (2021). "Farmakokutsadura eta Garapen Iraunkorrerako 6. Helburua: ur garbia eta saneamendua»; Ekaia, ale berezia 2021, 105-118. (https://doi.org/10.1387/ekaia.22086).
}

Jasotze-data: 2020, urriak 15; Onartze-data: 2021, urriak 04

ISSN 0214-9001 - elSSN 2444-3255 / (c) 2021 UPV/EHU

(i) (-) $\odot$ Lan hau Creative Commons Aitortu-EzKomertziala-LanEratorririkGabe 4.0 Nazioartekoa lizentzia baten mende dago 
Saioa Domingo Echaburu, Unax Lertxundi Etxebarria,

Gorka Orive Arroyo

\section{SARRERA}

\subsection{Farmakokutsadura. Kontzeptua eta garrantzia}

Geroz eta kutsatuagoa dagoen planeta baten bizi gara. Pestizidak, dioxinak, hidrokarburo aromatikoak, metal astunak... Hainbat substantzia erraz jotzen ditugu kutsatzailetzat. Ingurumenean duten presentzia arautua izan da hainbat legeren bidez. Azkenaldian, ordea, kutsatzaile izendatu berriez hitz egiten da, hots, aurretik ezezagunak ziren edo kutsatzailetzat jotzen ez ziren substantziez. Baliteke halakoek ingurumenean duten presentzia berria ez izatea, baina ingurumenean izan ditzaketen ondorioen gaineko kezka bada berria. Kutsatzaile horiek oso talde heterogeneoa osatzen dute, eta askotariko jatorri eta ezaugarri kimikoak dituzten konposatuak aurki ditzakegu haien artean, hala nola abusu-drogak, norbere higienerako produktuak, industria-erabilerako produktuak, eta farmakoak edo medikamentuak. Azken horiek dira kutsatzaile izendatu berrien artean kezka handiena eragiten dutenak. Izan ere, medikamentuen ingurumen-inpaktua aztertzea hainbat erakunderen (Osasunaren Mundu Erakundea - OME - eta Europako Batzordea tarteko) lehentasunezko ikerketa-ildo bihurtu da [1-2]. 2019an, Europako Batzordeak gai horri buruzko ikuspegi estrategikoa jasotzen duen dokumentua publikatu zuen [3]. Berriki, 2020ko irailean, Europar Parlamentuak farmakokutsadurari aurre egiteko neurri berriak eskatzeko ebazpena onartu zuen [4].

Farmako mota ugari dago. Europar Batasunean, esaterako, 3.000 printzipio aktibo baino gehiago daude komertzializatuta, eta, oro har, medikamentuen erabilera gora doa [1-2,5]. Gure inguruan, ezaguna da polimedikazioaren arazoa, batez ere pertsona nagusietan. Euskadin, 65 urtetik gorako pazienteen erdiei baino gehiagori 5 medikamentu edo gehiago preskribatzen zaizkie, eta datu hori handituz doa adinean gora goazen heinean (80 urtetik gorakoetan, \% 64 dira polimedikatuak) [6]. Mundu mailan ere medikamentuen kontsumoaren gorakada nabaria da: zenbatetsi da 2020an 4,5 bilioi medikamentu dosi erabiliko direla, uste da 2005ean populazioaren herenak egunero dosi bat baino gehiago kontsumitu zuela, eta aurreikusten da 2020an horrelakoen kontsumitzaileak populazioaren erdia baino gehiago izango direla [2]. Gizakiotan ez ezik, medikamentuak animalietan ere erabili ohi dira (maskotetan nahiz abeltzantzan). Europa mailan, animalietan erabiltzen diren medikamentuei buruzko kontsumo-datuei dagokionez, antibiotikoen salmenten datuak soilik daude eskuragarri. Haien arabera, oro har, saldutako antibiotiko kopurua jaitsi egin da azkenaldian (antibiotikoekiko erresistentzien kezkaren ondorioz). Halere, abelburuko kontsumoa gutxitu den arren, kopuru osoa igo liteke abelburu kopurua nabarmenki igoz gero [3]. 


\subsection{Medikamentuak naturan. Nola iristen diren eta zer eragin izan dezaketen}

Hainbat motatako medikamentu eta hondakinak hauteman dira mundu osoan zehar eta ingurumen-konpartimentu guztietan, batez ere uretan (hondakin-uretan, lurrazalekoetan nahiz lurpekoetan, edateko uretan). Lurzoruan, airean eta biotan ere ager daitezke [1-2, 5]. Aldizkari espezializatuetan publikatutakoaz gain, Alemaniako Ingurumen Agentziak ere jasotzen du informazio hori (dohainik eskuragarri: https://www.umweltbundesamt. de/dokument/database-pharmaceuticals-in-the-environment-excel).

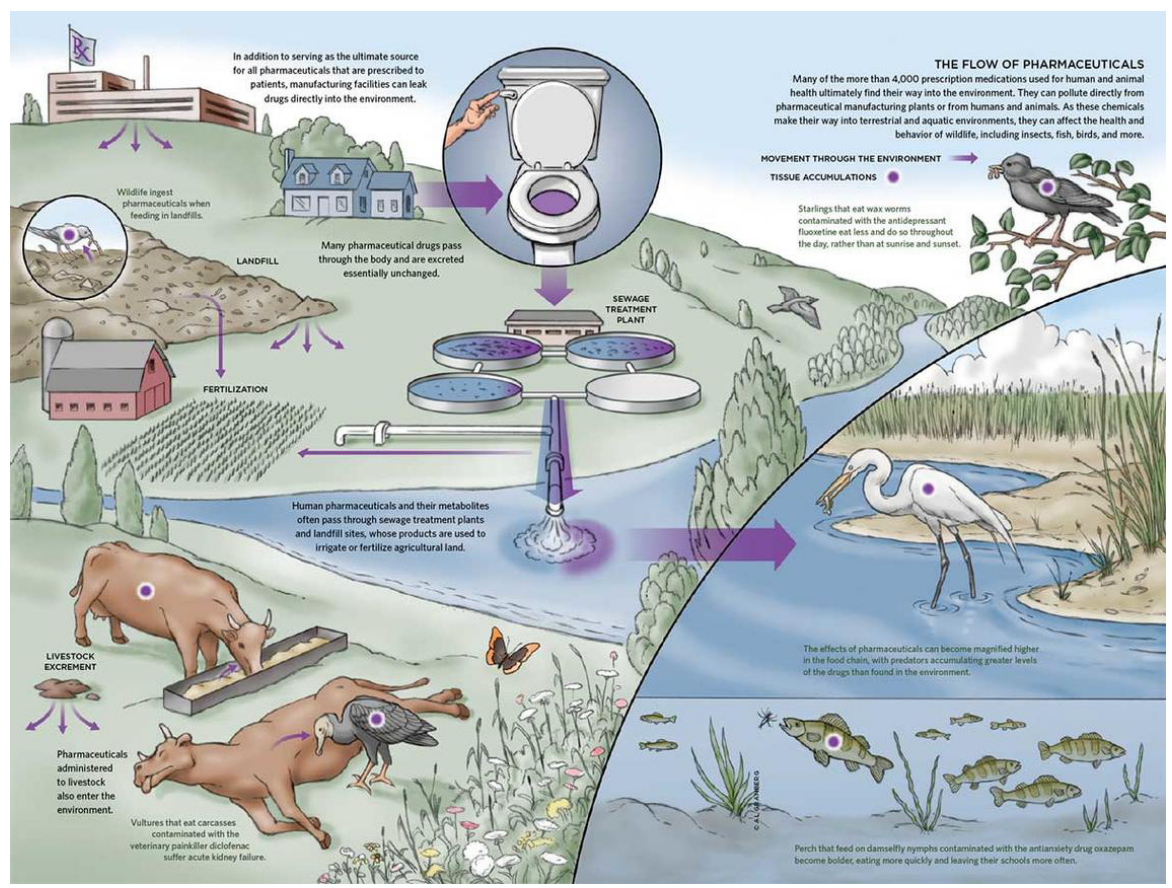

1. irudia. Medikamentuak naturan. Sarbideak eta eragina. Irudiaren egilea: $\mathrm{Al}$ Granberg (U.S. Geological Survey).

Medikamentuak ingurumenera iristeko bide nagusia kontsumoarekin eta haren ondoriozko farmako eta metabolitoen iraizpenarekin dago erlazionatuta [1-2,5]. Hau da, medikamentuak hartzean, zati bat organismotik kanporatzen da, bereziki gernuaren eta gorotzen bitartez, eta partzialki aktiboa izan daiteke oraindik ere [2]. Nolanahi ere, medikamentuen bizi-zikloaren beste faseetan ere gerta daitezke ingurumenerako igorpenak, hau da, produkzioan, banaketan eta hondakinen kudeaketan. Kontsumitu gabeko edo iraungitako medikamentuak komunetik eta hustubideetatik bo- 
Saioa Domingo Echaburu, Unax Lertxundi Etxebarria,

Gorka Orive Arroyo

tatzean, zuzenean sartzen dira ur-ingurumenera. Medikamentuen fabrikazioan sortutako hondakinak behar bezala kudeatzen ez badira, naturara isur daitezke [2,5]. Uraren saneamendurako, funtsezkoak dira ur-araztegiak. Hondakin-uren araztegietara, besteak beste, komun eta hustubideetatik jasotako ura iristen da, eta, bertan, medikamentuen hondakinak guztiz deusezten ez direnez, arazoa larriagotzen da.

Medikamentuak ingurumenean daudenean, konpartimentuen artean transferi daitezke. Adibidez, uretatik animalietara, eta, ondorioz, elikadura-kate trofikoetan hedatzen dira [2]. Plentziako Itsas Estazioan urraburuekin egindako esposizio-esperimentuak frogatu du amitriptilina (antidepresiboa), ziprofloxazinoa (antibiotikoa) eta oxibentzona (ultramore-iragazkia) arrainetan biometatzen direla, eta, horrez gain, kutsatzaile horiek albo-ondorioak eragiten dituztela arrainen plasman, burmuinean eta gibelean [7].

Izan ere, medikamentuek kontzentrazio oso baxuetan eragin dezakete, horretarako diseinatuak izan baitira [8]. Gizaki edo animalia batzuetan erabiltzeko pentsatuak izan arren, ez da harritzekoa medikamentuak beste izaki bizidun batzuekin kontaktuan jartzean haiengan ere eragina izatea. Farmakoek hainbat egitura edo sistematan eragiten dute, eta haietariko asko filogenetikoki kontserbatuta daude. Psikofarmakoen portaera-entseguak, adibidez, arrainetan egiten dira (Danio rerio), ugaztunetan egin beharrean [9].

Beharbada, farmakokutsaduraren ondoriozko kalteen adibiderik ezagunena etinilestradiol estrogenoari egotzitakoa da. Jakina da inguruneko etinilestradiolarekin kontaktuan egon diren arrainetan ugalketa-arazoak sortzen direla. Agian hain ezaguna ez dena, baina sarraski handia sortu zuena, mende hasieran diklofenakoak (antiinflamatorio ez-esteroideoa) Asiako saien espezie batzuen populazioan eragindakoa da. Saiak diklofenakoarekin kontaktuan jartzean, hil egiten ziren, eta, hain larria izan zen gertatutakoa, ezen sai espezie horietako batzuk - Gyps bengalensisa, esaterakogalzorian dauden espezieen zerrendan sartu baitziren, arrisku larriaren kategorian, eta, egun, oraindik ere, kategoria horretan jarraitzen dute [10]. Saiak diklofenakoarekin tratatutako abelburuen gorputz hilak jatean kutsatu ziren. Kutsatze-bidea ustekabekoa izan zen, eta adibide egokia da oraindik espezie batzuek farmako jakin bati izan diezaioketen berezko sentsibilitatea agerian uzteko $[1,2,11]$.

Europan, 2006az geroztik giza erabilerarako baimentzen diren medikamentuek ingurumenean izan dezaketen inpaktuari buruzko txostena aurkeztu behar dute, ERA izenekoa (ingelesezko Environmental Risk Assessment-etik eratorria). Txosten horien helburu nagusia ingurumenera isurtzen den sendagai kopurua txikiagotzea da, ingurumen-arriskuak murrizteko erabiltzaileek egin ditzaketen ekintza espezifikoak identifikatuz [1]. Alabaina, gaur egun kontsumitzen diren medikamentu asko legedia indarrean 
jarri aurretik merkaturatu ziren, eta ez dago haien ingurumen-inpaktuari buruzko informaziorik [5].

\section{GARAPEN IRAUNKORRERAKO AGENDA, URA ETA FARMAKOKUTSADURA}

2015ean, Nazio Batuen Erakundeak (NBE) Garapen Iraunkorrerako 2030 Agenda sortu zuen, herrialde guztietako pertsonen ongizatearen alde apustu egiteko aburuz. Horretarako, pobreziari aurre egitea, planeta zaintzea eta bakea eta oparotasuna bermatzea ezarri ziren xede gisa. Agenda horretan, garapen iraunkorrerako 17 helburu agertzen dira, eta helburu horiek aurrera eramateko 169 erronka. Helburuak eta erronkak integratuak eta banaezinak dira, eta garapen iraunkorraren hiru dimentsioak batzen dituzte: ekonomikoa, soziala eta ingurumenekoa [12]. Euskal Herriko Unibertsitateak $17+1$ helburu onartu zituen bere GIH 2030 agendan, euskararen eta euskal kulturaren garapena eta gaikuntza eleaniztuna gehituta [13].

Medikamentuei buruzko aipamena 3. helburuan agertzen da, bizimodu osasungarriari eta ongizateari lotuta. Hau da, kontuan hartzen dira medikamentuek gizakiongan dituzten efektu positiboak, baina ez ingurumenean izan ditzaketen ondorio kaltegarriak (farmakokutsadura). Halere, farmakokutsadura eta hura murrizteko ekintzen proposamenak hainbat helburu eta erronkatan aurki ditzakegu, kasu batzuetan zeharka bada ere. Adibidez, aipatzen da 3. helburua zuzenean oztopatzen duela antibiotikoekiko erresistentzien hedapenak, eta, NBEren arabera, munduko osasun publikoaren arazorik larriena da gaur egun. Arazo horren sortzailea, hein handi batean, antibiotikoen farmakokutsadura da. Helburu horrekin jarraituz, aipa genezake gaixotasun tropikal ahaztuentzat eta malariarentzat ematen diren farmako profilaktikoen erabilera masiboa. Osasunaren eta medikamentuen arteko erlazioa dirudien baino konplexuagoa izan daiteke, eta «One-Health» deritzon kontzeptuak berebiziko garrantzia du zentzu horretan, osasun bakarrean batzen baititu gizakion, animalien eta ingurumenaren osasuna [14].

Bestalde, badira urarekin zuzenean erlazionatutako bi helburu: 6. helburua (uraren erabilgarritasuna eta kudeaketa jasangarria nahiz guztiontzako saneamendua bermatzea) eta 14. helburua (ozeanoak, itsasoak eta itsas baliabideak mantentzea eta modu jasangarrian erabiltzea, garapen iraunkorrari begira). Azken horri dagokionez, 2020an, EKAIAk, itsas zientziei buruzko ale berezian, hainbat artikulu bildu zituen itsasoko kutsatzaileen inguruan, eta tarte berezia eskaini zien kutsatzaile izendatu berriei [15]. Itsasoko eta kostaldeko ingurumenean eragiten duen farmakokutsadurari buruzko 2014ko berrikuspena ere interesgarria da, gaiari sakonki heltzen dion heinean [16]. Aipagarria da, bestalde, iaz lehen aldiz 
Saioa Domingo Echaburu, Unax Lertxundi Etxebarria,

Gorka Orive Arroyo

hauteman zituztela kutsatzaile izendatu berriak (medikamentuak tarteko: fluoxetina eta norfluoxetina, serotoninaren birkaptazioaren inhibitzaile selektiboen - SBIS - taldeko antidepresiboak) Maldivetako koralezko arrezifeetako belakietan [17].

Farmakokutsadurak beste helburuetan ere eragin dezake. Berriki publikatutako artikulu batean aztertu da farmakokutsaduraren eta GIHen arteko lotura. Medikamentuek, eta batez ere farmakokutsadurak, 17 helburuetatik 12tan eragin dezake (2.,3.,4.,6.,7.,8.,9.,11.,12.,14.,15. eta 17.ean, hain zuzen ere), lehen begiratuan itxurazkoak ez diren moduetan (ikus 2. irudia). Beraz, farmakokutsadurari aurre egitea ezinbestekoa da GIHak lortzeko [18].

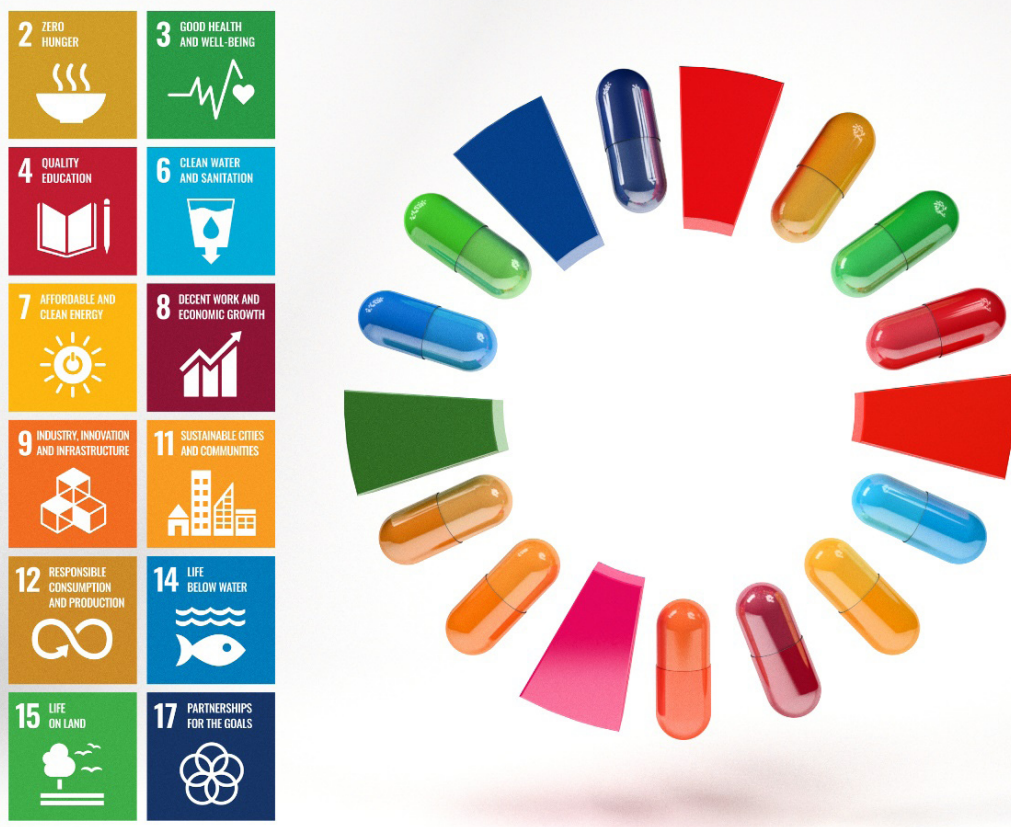

2. irudia. Farmakokutsadurak hainbat GIHtan eragin dezake.

Artikulu honetan, 6. helburua eta erronkak aztertuko ditugu, farmakokutsaduraren ikuspuntutik. 


\subsection{GIHa: farmakokutsaduraren ikuspuntua}

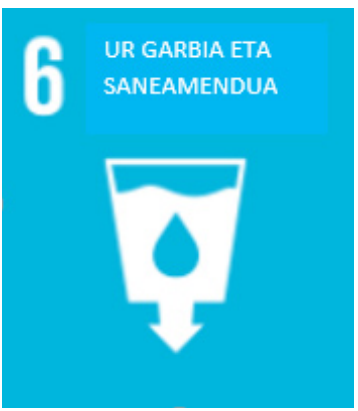

Jakina denez, ura beharrezkoa da izaki bizidunentzat. Urarekin erlazionatutako arazo nagusiak ur falta, uholdeak eta ur kutsatua dira.

Uraren erabilgarritasuna, saneamendua eta higienea giza eskubideak dira; halere, egunero milioika pertsonak zailtasun handiak dituzte oinarrizko zerbitzu horiek jasotzeko. NBEren datuen arabera, 10 pertsonatik 3k ez daukate bermatuta edateko ur segurua, eta 10etik $6 \mathrm{k}$ ez dute eskura segurtasunez kudeatutako saneamendu instalaziorik. Ur eskasiak munduko populazioaren \% 40ri baino gehiagori erasaten dio, eta ehuneko hori handitu daiteke [19]. Ikus 1. taula.

1. taula. Urarekin erlazionatutako arazoak eta kaltetutako populazioaren ehunekoa.

\begin{tabular}{lc}
\hline \multicolumn{1}{c}{ Arazoa } & Kaltetutako populazioa \\
\hline Edateko ur segururik eza & $\% 33$ \\
Ur-saneamendu segururik eza & $\% 60$ \\
Ur eskasia & $\% 40$ \\
\hline
\end{tabular}

6. GIHaren erronken artean, farmakokutsaduraren murrizketarekin zuzenean lerrokatzen direnak aipatuko ditugu. Kontuan hartu beharrekoa da gai horri buruzko hainbat alderdi hainbat erronkatan garatzen direla.

\subsubsection{2. erronka: hemendik 2030era saneamendu-eta higiene-zerbitzu} egoki eta bidezkoetarako sarbidea lortzea denontzat, eta amaiera ematea aire zabalean sabelusteari.

NBEren datuen arabera, 673 milioi pertsonak praktikatzen dute aire zabaleko sabelustea, eta haien \% 91 landa-eremuetan bizi dira. Gizarte batzuetan sustraitutako arau kulturala da. Praktika hori murrizten ari bada ere, 
Saioa Domingo Echaburu, Unax Lertxundi Etxebarria,

Gorka Orive Arroyo

egoera kezkagarria da, batez ere erdialdeko eta hegoaldeko Asian, ekialdeko eta hego-ekialdeko Asian eta Saharaz hegoaldeko Afrikan, eta, hori geldiarazteko, komunitate osoaren portaera aldatu behar da, eta inbertsioa egin komunak eta bestelako oinarrizko zerbitzu batzuk eraiki, mantendu eta erabiltzeko [19]. Izan ere, gernu eta gorotzen bidez kanporatzen diren medikamentuak eta haien hondakinak zuzenean sartzen dira ingurumenera, lurzorutik uretara filtratuz edo zuzenean uretara sartuz. Aire zabalean sabelustea ahal den neurrian murriztuko balitz, kutsatze-bide horren garrantzia minimizatuko litzateke.

\subsubsection{3. erronka: hemendik 2030era uraren kalitatea hobetzea; alegia: kutsadura murriztea; hondakin, produktu kimiko eta material arriskutsurik ez isurtzea; tratatu gabeko hondakin-uren portzentajea erdira murriztea; eta arriskurik gabeko birziklapena eta berrerabilera nabarmen areagotzea mundu osoan.}

NBEren dokumentuaren arabera, ur kutsatuaren ondorioen artean, beherakoa aipatzen da. Izan ere, uraren saneamendu faltarekin erlazionatutako gaixotasunak 5 urtetik beherako haurren heriotza-kausa nagusietakoak dira, eta egunero 800 haur baino gehiago hiltzen da munduan higiene ezaren ondorioz sortutako beherakoengatik [19]. Aurrez adierazi bezala, NBEren dokumentuan ez da farmakokutsadura zuzenean aipatzen uraren kutsadurari buruz aritzean, nahiz eta ezin den haren garrantzia gutxietsi uraren kalitateari dagokionez. 2012ko OMEren edateko urari buruzko txostenak ondorioztatu zuen edateko uretan atzemandako farmakoen mailak ez liratekeela gizakiontzako kaltegarriak [20]. Halere, kezka sortzen du hainbat kutsatzaileren (nahasketaren) esposizio kronikoak gure osasunean izan dezakeen eraginak [5].

Giza jarduerak sortutako hondakin-uren $\% 80$ baino gehiago zuzenean isurtzen dira ibaira edo itsasora, inolako tratamendurik gabe, eta urak kutsatzen dira [19]. Erronka horren helburuetako bat ehuneko hori gutxitzea da.

Ibai, laku eta akuiferoetatik hartutako uraren $\% 70$ gutxi gorabehera ureztapenerako erabiltzen da [19]. Ur eskasiari aurre egiteko neurrien artean, uraren berrerabilera sustatzea proposatzen da. Hondakin-urek hainbat erabilera izan ditzakete, hala nola nekazaritzan (ureztapenerako), industrian zein aisialdian. Hondakin-urak birziklatzea ekonomia zirkularrean oinarritzen da. Alde horretatik, hondakin-urak segurtasunez berrerabiltzeko bete beharko liratekeen gutxieneko baldintzak arautu berri ditu Europar Batasunak [21]. Baldintza horien artean ez dago farmakoen monitorizaziorik. Gurera etorrita, Aclima-Basque Environment Cluster-ek eta Uraren Euskal Agentziak (URA) elkarlanean jardungo dute hondakin-uren araztegietan tratatutako urak industrian berrerabili ahal izateko, segurtasuna bermatuz. Horrela, baliabide hidrikoak modu eraginkorrean erabiltzea sustatzen da [22]. 


\subsubsection{6. erronka: hemendik 2030era babestea eta berrezartzea urarekin} lotura duten ekosistema, baso, mendi, hezegune, ibai, akuifero eta lakuak.

Sarreran aipatu bezala, izaki bizidunen artean diana terapeutikoak partekatzen ditugu, eta, ondorioz, medikamentuek eragina izan dezakete medikamentu horiek hartzea espero ez den izakietan ere. Farmakokutsadurak hainbat ekosistema motatan izan ditzakeen eraginen inguruko ikerketa sustatu behar da, ekosistema horiek babestu ahal izateko. Jakina da farmakokutsadurak eragina izan dezakeela ekosistema akuatikoetan; horren adibide dira aurrez aipatu dugun etinilestradiolak arrainengan eragiten dituen ugalketa-arazoak, eta beste hainbeste: SBIS taldeko antidepresiboek zebra-muskuiluen ugalketa estimulatzea [1], fluoxetinarekin (SBIS taldeko antidepresiboetako bat) kontaktuan egondako lupien harrapaketa-ahalmena gutxitzea [1], sinbastatina hipolipemiatzailearekiko esposizio kronikoak krustazeoen ugalketa eta garapena aldatzea [23], eta abar. Deigarria da ikertutako farmako batzuek denbora luzez irauten dutela ingurumenean; oxazepam izeneko antsiolitikoa, kasurako. Suediako lakuetan egindako ikerketa batean frogatu da 1970eko hamarkadan erabilitako oxazepama atzeman dutela 2013an ateratako laginetan [24].

Oraindik ere, asko dago ikertzeko farmakokutsaduraren inguruan. Orokorrean, ikuspuntu antropozentrista gailentzen da, hots, farmakokutsadurak gizakiongan izan dezakeen eragina da kezka gehien sortzen diguna, eta beste espezie eta ekosistemetan izan dezakeen ondorioetan atentzio gutxiago jartzen da. Planeta berean bizi gara, ordea. Zer eragin izan lezake ekosistema bat eraldatzeak edo desagertzeak? [2, 25].

\subsubsection{6.a erronka: hemendik 2030era nazioarteko lankidetza eta garapen-} bidean dauden herrialdeei emandako laguntza areagotzea, uraren eta saneamenduaren arloko jarduera eta programetan ahalmena sortzeko; esaterako, honako hauetan: ura jasotzea, gatzgabetzea, baliabide hidrikoak modu eraginkorrean erabiltzea, hondakin-urak tratatzea, birziklatzea eta berrerabiltzeko teknologiak erabiltzea .

Erronka hori zuzenean erlazionatuta dago hondakin-uren araztegiekin. Aipatu bezala, naturan, batez ere uretan atzematen dira medikamentuak, eta ur-ingurumenerako sarbide nagusietako bat hondakin-urak dira. Askotariko jatorriak izan ditzakete: hirikoak, ospitalekoak, industriakoak, nekazaritzakoak, abeltzantzakoak.

Hondakin-uren araztegiak ez ziren diseinatu medikamentuen hondakinak deuseztatzeko, konposatu organikoak naturan izango lituzketen biodegradazio-prozesuak imitatzeko baizik [11]. Gainera, 6.3 erronkan aipatu bezala, munduko hondakin-uren $\% 80 \mathrm{ez}$ da araztegietatik pasatzen, eta urekosistemak zuzenean kutsatzen dira. 
Saioa Domingo Echaburu, Unax Lertxundi Etxebarria,

Gorka Orive Arroyo

Hondakin-uren araztegietan, zenbait teknika erabiltzen dira kutsatzaileak murrizteko: bigarren mailakoa (tratamendu biologikoa) eta hirugarren mailako tratamenduak (ozonizazioa, karbono-aktibatuan adsortzioa, nanofiltrazioa, etab.). Tratamendu horiei esker, gerta daiteke kutsatzaileak uretatik lokatzetara pasatzea eta ondorioz araztegietako efluenteetatik desagertzea [11]. Hainbat herrialdetan, baimenduta dago araztegietan sortutako lokatzak nekazaritzan erabiltzea, ongarri gisa.

Ur-araztegietan erabiltzeko teknologien berrikuntzen artean, nabarmentzekoa da White rot funghi izeneko onddoei buruzko ikerketa. Onddo horiek entzima oxidatzaile inespezifikoak dituzte, eta entzima horiek materia organikoa degradatzeko balio dute. Halakoak erabiliz gero, farmakoez gain, beste kutsatzaile izendatu berrien presentzia ere murriztu daiteke, eta uraren kalitatea nabarmenki hobetu [26].

Afrikako eta Europako ur gezetako farmakokutsadura aztertzen duen ikerlan baten arabera, Afrikan hautemandako kontzentrazio maximoak Europan atzemandakoak baino 20.000 bider altuagoak direla frogatu da, eta horren arrazoien artean hondakin-uren araztegietako deusezte partziala aipatzen dute. Afrikan, hondakin-uren tratamendua hobetu beharra premiazkoa dela ondorioztatu dute [27].

Bestalde, farmakokutsadurari aurre egiteko, funtsezkoa da farmakoen detekzioa eta monitorizazioa sustatzea [3]. Horretarako, beharrezkoa da teknika analitiko egokiak prest izatea. Horrek araztegietara heltzen diren medikamentu eta hondakinen tratamendua eraginkorra den ala ez aztertzea erraztuko luke.

Baliabide hidrikoak modu eraginkorrean erabiltzeari dagokionez, 6.3. erronkan aipatu bezala, hondakin-uren berrerabilpena baliagarri izan daiteke.

\section{ZER EGIN DEZAKEGU? ARAZOARI AURRE EGITEKO PROPOSAMENAK}

Uretako farmakokutsadura murrizteko, askotariko neurriak proposatu izan dira. Lekuan lekuko osasun publikoaren beharrak eta proposatutako neurrien kostu-eraginkortasuna kontuan hartu beharreko faktoreak dira, neurrien bideragarritasuna bermatzeko (adibidez, araztegiak hobetzeko beharrezko teknologia garestiegia bada, hobekuntza hori ezin eramango da aurrera zenbait herrialdeetan) [3].

Prebentzio-neurri gisa, medikamentuen bizi-zikloaren hasieran eragin dezakegu; adibidez, medikamentu «berdeagoak» diseinatuz, hots, biodegradagarriak, naturan meta ez daitezen $[2,3]$. 
Bestalde, medikamentuen gehiegizko kontsumoa ekiditeko, ezinbestekoa da erabilera arrazionala sustatzea, eta iraungitako edo kontsumitu gabeko medikamentuak egokiro baztertzeaz kontzientziatu behar dira pazienteak zein osasun-profesionalak [2, 3].

Medikamentuen ingurumen-inpaktuaren gaineko ezagutza hobetzea ere ezinbestekoa da. ERAk hobetu behar lirateke, eta medikamentu zaharren kasuan ere ERAk sustatu behar lirateke. Ikerketa ekotoxikologiko gehiagoren beharra dago arazoa sakonkiago ezagutu ahal izateko $[1,3]$.

Beharrezkoa da hondakin-uren araztegietako tekniken inguruko ikerketa sustatzea, tratamendu eraginkorragoak erabil daitezen. Horrekin batera, araztegietako tratamenduen eraginkortasuna neurtzeko, ezinbestekoa da medikamentuen eta hondakinen detekziorako teknika analitiko egokiak sustatzea. Hala ere, hainbat herrialdetan ez dago hondakin-uren araztegirik, edota erabiltzen diren tratamenduak ez dira nahiko, eta gabezia horri aurre egitea lehentasunezkoa da [25]. Dena dela, «end-of-pipe» neurriak, hau da, prozesuaren bukaerakoak (adibidez, hondakin-uren tratamendua hobetzea), beste neurri batzuekin batera hartu beharrekok dira (produkzio eta erabilera mailakoak, esaterako), inolaz ere ez bakarka [3].

Herbehereetan, kate-estrategia proposatu dute uretako farmakokutsadura murrizteko, eta kontuan hartu dute medikamentuen bizi-zikloan parte hartzen duten agente guztien partaidetza [28]. Alde horretatik, deigarria da osasun-arloko profesionalek, medikamentuen erabileran adituenak izanik ere, orokorrean medikamentuek naturan duten inpaktuaren inguruan duten ezagutza falta. Arazoa konpontzeko, nahitaezkoa da kontzientzia garatzea eta beste eragileekiko elkarlana sustatzea $[29,30]$.

\section{AZKEN GOGOETAK}

GIHak mundu osorako garrantzitsuak badira ere, garrantzi berezia dute garapen-bidean dauden herrialdeetan, eta horiek dira, hain zuzen ere, uretako farmakokutsadura gehien dutenak [27]. Arrazoien artean, medikamentuen kontsumoaren gorakadaz gain, monitorizazio eta kontrol eskasa leudeke (lege falta). Hala, funtsezkoa izango da, besteak beste, 6. GIHan aipatzen diren erronka hauek aurrera eramatea: aire zabaleko sabelusteak murriztea, tratatu gabeko hondakin-urak gutxitzea, hondakin-uren araztegietako tratamenduak hobetzea, uren birziklapen eta berrerabilpen segurua bermatzea, eta urarekin erlazionaturiko ekosistemak babestu eta berrezartzea.

Oro har, farmakokutsadura «arazo gaiztoa» ere izendatu izan da (ingelesez, «wicked problem»), konplexua, aurresanezina eta zehaztugabea delako. Arazoaren ezaugarrien artean, ziurgabetasun zientifikoa, orotariko 
Saioa Domingo Echaburu, Unax Lertxundi Etxebarria,

Gorka Orive Arroyo

balio eta interesak dituzten eragile ugarien presentzia eta konplexutasun instituzionala ageri dira [28]. Dena dela, ezin ahaztu dezakegu uraren farmakokutsadura mundu mailako arazoa dela eta gizakion oinarrizko eskubideak urratzen dituela (uraren erabilgarritasuna, saneamendua eta higienea), eta, beraz, 6. GIHaren lorpena zuzenean mehatxatzen duela. Gainera, ondorio kaltegarriak izan ditzake ingurumenean. Alde horretatik, «One-Health» ikuspuntua (osasun bakarrean biltzea gizakiona, animaliena eta ingurumenarena) estrategia jarraitu behar dela deritzogu. Hori dela eta, ezinbestekoa da arazoari aurre egiteko konponbideak jorratzea, kontzientziazioa eta ikerketa sustatuz, medikamentuen bizi-zikloan parte hartzen duten eragile guztien arteko elkarlanean.

\section{BIBLIOGRAFIA}

[1] 2016. «Farma-kutsadura. Sendagaien ingurumen-inpaktua». INFAC, 24,10.

[2] DOMINGO ECHABURU, S; LERTXUNDI ETXEBARRIA, U eta ORIVE ARROYO, G. 2020. «Farmakokutsadura: medikamentuak ere naturaren kutsatzaile?!». Elhuyar aldizkaria, 339, 80-85.

[3] EUROPAKO BATZORDEA. 2019. Communication from the Commission to the European Parliament, the Council and the European Economic and Social Commitee. «European Union Strategic Approach to Pharmaceuticals in the Environment». Eskuragarri: https://ec.europa.eu/environment/water/ water-dangersub/pdf/strategic_approach_pharmaceuticals_env.PDF (eguneratze-data: 2020/09/14)

[4] EUROPAKO PARLAMENTUA. Eskuragarri: https://www.europarl.europa. eu/news/en/press-room/20200910IPR86826/parliament-wants-the-eu-to-tackle-pharmaceutical-pollution (eguneratze-data: 2020/09/28).

[5] BIO INTELLIGENCE SERVICE. 2013. «Study on the environmental risk of medicinal products. Final report» prepared for Executive Agency for Health and Consumers. Eskuragarri: https://ec.europa.eu/health/sites/health/ files/files/environment/study_environment.pdf (2020/09/15) .

[6] OBIEEko preskripzio-datuak. Asistentzia Sanitarioko Zuzendaritza. Osakidetza. (2019-12-03an kontsultatua).

[7] ZIARRUSTA,H; RIBBENSTEDT, A; MIJANGOS, L; PICART-ARMADA, S; PERERA-LLUNA, A; PRIETO, A; IZAGIRRE, U; BENSKIN, JP; OLIVARES, M; ZULOAGA, O eta ETXEBARRIA, N. 2019. «Amitriptyline at an Environmentally Relevant Concentration Alters the Profile of Metabolites Beyond Monoamines in Gilt-Head Bream». Environ Toxicol Chem, 38, 965-977.

[8] DAUGHTON, CG eta TERNES, TA. 1999. «Pharmaceuticals and personal care products in the environment: agents of subtle change?». Environ Health Perspect, 107, 907-38. 
[9] STEWART, A; WU, N; CACHAT, J; HART, P; GAIKWAD, S; WONG, K; UTTERBACK, E; GILDER, T; KYZAR, E; NEWMAN, A; CARLOS, D; CHANG, K; HOOK, M; RHYMES, C; CAFFERY, M; GREENBERG, M; ZADINA, J eta KALUEFF, AV. 2011. «Pharmacological modulation of anxiety-like phenotypes in adult zebrafish behavioral models». Progress in Neuro-Psychopharmacology \& Biological Psychiatry, 35, 1421-1431.

[10] I UCIN. Eskuragarri: https: / / w w wiucnredlist.org/ species/22695194/118307773 (eguneratze-data: 2020/09/21).

[11] HESTER, ER eta HARRISON, RM. 2016. Pharmaceuticals in the Environment. The Royal Society of Chemistry, Cambridge.

[12] NAZIO BATUEN ERAKUNDEA. 2015. «Gure mundua eraldatzea: 2030 Agenda, Garapen jasangarrirako». UNESCO Etxea. Euskarazko itzulpena. Jatorrizko dokumentua eskuragarri: https://sustainabledevelopment.un.org/ post2015/transformingourworld/publication (eguneratze-data: 2020/09/28)

[13] EHU. «EHUagenda2030». Eskuragarri: https://www.ehu.eus/es/web/ iraunkortasuna/ehuagenda-2030 (eguneratze-data: 2021/09/21)

[14] ORIVE, G eta LERTXUNDI, U. 2020. «Mass drug administration: time for considering drug pollution?». The Lancet, 395,1112.

[15] 2020. EKAIAren ale berezia: «Itsas Zientziak».

[16] GAW, S; THOMAS, KV eta HUTCHINSON, TH. 2014. «Sources, impacts and trends of pharmaceuticals in the marine and coastal environment». Philos Trans R Soc Lond B Biol Sci, 369, 20130572.

[17] RIZZI, C; SEVESO, D; GALLI, P eta VILLA, S. 2020. «First record of emerging contaminants in sponges of an inhabited island in the Maldives». Mar Pollut Bull, 156,111273.

[18] DOMINGO-ECHABURU, S; DÁVALOS, LM; ORIVE, G eta LERTXUNDI, U. 2021. «Drug pollution \& Sustainable Development Goals». Sci Tot Env. 800, 149142.

[19] NAZIO BATUEN ERAKUNDEA. Eskuragarri: https://www.un.org/sustainabledevelopment/es/water-and-sanitation (Eguneratze-data: 2021/09/21).

[20] OSASUNERAKO MUNDU ERAKUNDEA. 2012. «Pharmaceuticals in drinking-water» Eskuragarri: https://apps.who.int/iris/bitstream/handle/1066 5/44630/9789241502085_eng.pdf?sequence=1\&isAllowed=y. (Eguneratzedata: 2020/9/25).

[21] EUROPAKO BATZORDEA. Eskuragarri: https://ec.europa.eu/environment/ water/reuse.htm (Eguneratze-data: 2020-9-25).

[22] URA. Eskuragarri: https://www.residuosprofesional.com/aclima-ura-reutilizacion-aguas-residuales (Eguneratze-data: 2020/09/28).

[23] SANTOS, MM; RUIVO, R; LOPES-MARQUES, M; TORRES, T; DE LOS SANTOS, CB; CASTRO, LF eta NEUPARTH, T. 2016. «Statins: An undesirable class of aquatic contaminants?». Aquat Toxicol, 174, 1-9.

[24] KLAMINDER, J; BRODIN, T; SUNDELIN, A; ANDERSON, NJ; FAHLMAN, J; JONSSON, M et al. 2015. «Long-term persistence of an anxio- 
Saioa Domingo Echaburu, Unax Lertxundi Etxebarria,

Gorka Orive Arroyo

lytic drug (oxazepam) in a large freshwater lake». Environ Sci Technol, 49, 10406-12.

[25] ORIVE, G; LERTXUNDI, U. 2019. «Virus, bats and drugs». Reviews on the Environmental Health, 4, 31.

[26] CRUZ DEL ALAMO, A, PARIENTE, MI; MARTÍNEZ, F eta MOLINA R. 2019. «Trametes versicolor immobilized on rotating biological contactors as alternative biological treatment for the removal of emerging concern micropollutants». Water research, 170, 115313.

[27] FEKADU, S; ALEMAYEHU, E; DEWIL, R eta VAN DER BRUGGEN, B. 2019. «Pharmaceuticals in freshwater aquatic environments: A comparison of the African and European challenge». Science of the Total Environment, 654, 324-337.

[28] HERBEHEREETAKO GOBERNUA. «Reducing pharmaceutical residues in water: a chain approach». Eskuragarri: https://www.government.nl/documents/policy-notes/2019/02/12/reducing-pharmaceutical-residues-in-watera-chain-approach (Eguneratze-data: 2020/9/25).

[29] LERTXUNDI, U; DOMINGO-ECHABURU, S eta ORIVE, G. 2020. «It's about time healthcare professionals and academics start thinking about drug pollution». Sustainable Chemistry \& Pharmacy, 16, 100278.

[30] LERTXUNDI, U; HERNANDEZ, R; MEDRANO, J. eta ORIVE, G. 2020. «Drug pollution and pharmacotherapy in psychiatry: a platypus in the room». European Psychiatry, 6, e33. 